\title{
Characteristic expression and significance of CCL19 in different tissue types in chronic rhinosinusitis
}

\author{
YOU ZOU ${ }^{1 *}$, YAN WANG $^{1^{*}}$, SHUI-BIN WANG ${ }^{2}$, YONG-GANG KONG $^{1}$, \\ YU XU ${ }^{1}$, ZE-ZHANG TAO $^{1}$ and SHI-MING CHEN ${ }^{1}$ \\ ${ }^{1}$ Department of Otolaryngology-Head and Neck Surgery, Renmin Hospital of Wuhan University, Wuhan, Hubei 430060; \\ ${ }^{2}$ Department of Otolaryngology-Head and Neck Surgery, Yichang Yiling Hospital, Yichang, Hubei 443100, P.R. China
}

Received July 5, 2015; Accepted October 30, 2015

DOI: $10.3892 /$ etm.2015.2897

\begin{abstract}
Chronic rhinosinusitis (CRS) is a heterogeneous disease, with varying immunological and histopathological features. The CC chemokine ligand 19 (CCL19) can stimulate $\mathrm{T}$ cells and antigen-presenting cells into secondary lymphoid node formation, as observed in allergic rhinitis, inflammatory bowel disease and other inflammatory disorders. The purpose of this study was to investigate the expression and significance of CCL19 in CRS. Samples of uncinate process mucosa or nasal polyps were taken from patients with CRS (without or with nasal polyps) and normal controls during surgery. Hematoxylin and eosin, periodic acid Schiff and Masson trichrome staining were used for analysis of the nasal polyps. Western blot and immunofluorescence were used to detect CCL19 expression in the nasal polyps and normal nasal mucosa tissues. Spearman correlation analysis was used to analyze the association between CCL19 and blood eosinophil counts. The results showed that CCL19 protein levels in CRS (with or without nasal polyps) were significantly upregulated compared with those in controls. CCL19 expression in eosinophilic CRS was significantly higher than in non-eosinophilic CRS. CCL19 expression in fibroinflammatory and edematous type CRS with nasal polyps was higher than in controls; the upregulation was greater in the edematous type. Immunofluorescence assays showed that CCL19 was mainly expressed by CD68 ${ }^{+}$ macrophages. Spearman correlation analysis demonstrated a positive correlation between CCL19 and blood eosinophils. The upregulation of CCL19 in CRS may play a protective role
\end{abstract}

Correspondence to: Professor Shi-Ming Chen, Department of Otolaryngology-Head and Neck Surgery, Renmin Hospital of Wuhan University, 99 Zhang Zhi Dong Street, Wuhan, Hubei 430060, P.R. China

E-mail: shimingchen0468@163.com

*Contributed equally

Key words: chemokine, CC chemokine ligand 19, chronic rhinosinusitis, nasal polyps, eosinophils by limiting eosinophil infiltration and the extent of edema to exert anti-inflammatory and immunomodulatory effects.

\section{Introduction}

Chronic rhinosinusitis (CRS), characterized by chronic inflammation of the nasal cavity and paranasal sinus mucosa, remains a significant health problem with a considerable socioeconomic burden and is increasing in prevalence and incidence. Shi et al (1) have demonstrated that the overall prevalence of CRS is currently $8 \%$ (range, $4.8-9.7 \%$ ) in seven cities in mainland China. At present, the pathogenesis of CRS remains unclear. Many studies support the hypothesis that allergens, bacterial, fungal infection and nasal anatomic abnormality all play an important role (2-4).

CRS is commonly divided into two categories: CRS without nasal polyps (CRSsNP) and with nasal polyps (CRSwNP), the former being dominated by Th1, while the latter mainly manifests Th2 responses $(2,5)$. Nasal polyps are usually derived from the ostiomeatal complex, particularly the uncinate mucosa. CRSwNP can be further divided into eosinophilic or non-eosinophilic types, according to the degree of infiltrative eosinophilia. CRSwNP in patients from Western countries is typically eosinophilic and Th2-focused, whereas it is mainly neutrophilic and Th1-focused in Asian populations $(6,2)$. CRSwNP, can be further divided into three types, namely seromucinous, fibroinflammatory and edematous according to the degree of tissue remodeling $(7,8)$. Chemokines, cytokines and other inflammatory mediators, including $\mathrm{T}$ cells, eosinophils, neutrophils, and macrophages $(2,9)$, play a key role in mediating the migration and invasion of these inflammatory cells, eventually leading to tissue remodeling and CRS development (10-13).

Chemokines are able to combine with G-receptor proteins on target cells and play an important role in the development and regulation of the immune response by bringing inflammatory cells into the site of inflammation (10-17). CC chemokine ligand 19 (CCL19), also known as macrophage inflammatory protein (MIP)-3 $\beta$, is a chemokine of molecular weight $11 \mathrm{kDa}$. CCL19 has multiple effects and can act as a chemotactic signal for various immune cells, including dendritic cells, $\mathrm{T}$ cells, B cells, natural killer cells and macrophages (18-20). Through interaction with its receptor (CC chemokine receptor 7), 
CCL19 has an immunostimulatory effect, promoting contacts between dendritic cells and $\mathrm{T}$ cells, and promoting antigen presentation (21). Simultaneously, CCL19 can also exert an immunosuppressive effect through the production of interleukin (IL)-10, the restriction of movement of dendritic cells, and the induction of apoptosis of mature dendritic cells $(22,23)$. Knockout mice for CCL19 have a significant delay in the resolution of lung inflammation, accompanied by the downregulation of IL-10 expression (22). In addition, clinical studies have indicated that CCL19 is involved in allergic rhinitis, inflammatory bowel disease and other inflammatory and immune disorders $(24,25)$. However, the expression and possible role of CCL19 in CRS are not currently described. Therefore, this study aimed to analyze the differential expression of CCL19 in normal nasal mucosa and in different types of CRS and to explore its significance in the pathophysiology of this condition.

\section{Materials and methods}

Subjects and samples. Samples were taken from patients undergoing endoscopic nasal surgery at the Department of Otolaryngology-Head and Neck Surgery of the Renmin Hospital of Wuhan University (Wuhan, China), between June 2013 and December 2013. Tissue specimens of CRSwNP were from 71 patients, of whom 47 were male and 24 female. Eleven of these cases had a history of allergic rhinitis or asthma. Tissue specimens for CRSsNP were obtained from 21 patients, of whom 11 were male and 10 were female. The normal control group included 20 cases (13 male and 7 female). The diagnosis of CRS in all cases was made according to the recommended European diagnostic standard EPOS2012 (26). Patients were excluded if they had a history of autoimmune disease, the 'aspirin triad', primary cilia motility dysfunction or cystic fibrosis, or had a history of intranasal or oral corticosteroid use in the 2 weeks prior to the surgery. During the surgery, polyps were taken from patients with CRSwNP, and a biopsy of the uncinate process mucosa was made from patients with CRSsNP and those with nasal septum deviation. The specimens were divided into two parts. One was reserved in liquid nitrogen, while the other was fixed in $4 \%$ paraformaldehyde for $24 \mathrm{~h}$ prior to embedding in paraffin. This study was approved by the Ethics Committee of Renmin Hospital of Wuhan University (approval number: 20130308). Informed consent was obtained from every subject.

Paraffin section staining. Serial sections were made from each specimen, with a thickness of $5 \mu \mathrm{m}$, for Masson trichrome, hematoxylin and eosin (H\&E) and periodic acid Schiff (PAS) staining (all Wuhan Jiayuan Quantum Dots Co., Ltd., Wuhan, China). All stains were performed in accordance with the manufacturer's protocol. The analysis of nasal polyp tissue morphology and eosinophil classification were performed as previously described in the literature $(2,8,9)$.

Western blot analysis to detect the expression of CCL19 protein. The tissues were cut into pieces, and $250 \mu 1$ lysis buffer (ab204733; Abcam, Cambridge, UK), containing $1 \mathrm{mM} \mathrm{MgCl} 2,10 \mathrm{mM}$ Tris- $\mathrm{HCl}$ (pH 7.4), $1 \%$ Triton X-100, $1 \%$ sodium dodecyl sulfate (SDS) and $1 \%$ NP-40, was added for every $20 \mathrm{mg}$ tissue. The sample was then centrifuged at $4^{\circ} \mathrm{C}, 12000 \mathrm{x} \mathrm{g}$ for $15 \mathrm{~min}$, and the supernatant was isolated. The bicinchoninic acid method was used to determine the concentration of total protein in the sample. For this, 12\% SDS-polyacrylamide gel (Thermo Fisher Scientific Inc., Waltham, MA, USA) and spacer gel were prepared and the amount of protein loaded for each lane was quantified at $25 \mu \mathrm{g}$. The spacer gel was run at $75 \mathrm{~V}$ for $30 \mathrm{~min}$, and the separation gel was run at $120 \mathrm{~V}$ for $60 \mathrm{~min}$; the transfer was performed at $200 \mathrm{~mA}$ for $30 \mathrm{~min}$, and blocking was undertaken using $5 \%$ skimmed milk powder at $4^{\circ} \mathrm{C}$ overnight. The membrane was subsequently incubated with primary mouse anti-CCL19 monoclonal antibody (ab193000) at a dilution of 1:500 $(0.2 \mu \mathrm{g} / \mathrm{ml})$ for $2 \mathrm{~h}$ at room temperature. Mouse anti- $\beta$-actin monoclonal antibody (1:1,000; ab123034) was used as a loading control. A horseradish peroxide (HRP)-conjugated secondary antibody (1:1,000; ab131368; all Abcam) was incubated with the membrane for $1 \mathrm{~h}$ at $37^{\circ} \mathrm{C}$. Enhanced chemiluminescence detection (12630S; Cell Signalling Technology, Inc., Danvers, MA, USA) was used to observe the blots. The densitometry of the bands was quantified using ImageJ 2X software (National Institutes of Health, Bethesda, MA, USA).

Paraffin section immunofluorescence. Paraffin sections were dewaxed to permit water penetration, and underwent high temperature microwave repair for $10 \mathrm{~min}$. Blocking was conducted by incubation with normal sheep serum (Gibco; Thermo Fisher Scientific, Inc.) for $30 \mathrm{~min}$. The following primary mouse monoclonal antibodies were incubated with the sections for $1 \mathrm{~h}$ at room temperature: Rat anti-cluster of differentiation (CD68) $(1: 100,1 \mu \mathrm{g} / \mathrm{ml}$; ab31630) and rabbit anti-CCL19 (1:100, $1 \mu \mathrm{g} / \mathrm{ml}$; ab126742; both Abcam). A wash with $0.01 \mathrm{M}$ phosphate-buffered saline (PBS) was conducted. Fluorescein isothiocyanate (FITC)-labeled goat anti-rabbit immunoglobulin (Ig)M (1:100; LS-C86590-2000) and Luo Danming (Rhodamine)-labeled goat anti-rat IgG secondary antibodies (1:100; LS-C61649-1000; both LifeSpan BioSciences, Inc., Seattle, WA, USA) were added to the sections and incubated for $1 \mathrm{~h}$ at room temperature. After a further wash with $0.01 \mathrm{M}$ PBS, the samples were counterstained with 4,6-diamidino-2-phenyl indole and images were captured using an upright Olympus BX61 fluorescence microscope (Olympus Corporation, Tokyo, Japan).

Statistical analysis. Experimental results were expressed as median values and SPSS software (version 17.0; SPSS, Inc., Chicago, IL, USA) was used to conduct statistical analyses. Independent samples were compared with the t-test and the Spearman correlation coefficient was used to analyze the association between CCL19 and eosinophils in the blood. In addition, non-parametric Kruskal-Wallis tests were used to analyze the expression levels of CCL19. P $<0.05$ was considered to indicate a statistically significant result.

\section{Results}

Inflammation and tissue typing of chronic rhinosinusitis. In accordance with previously used eosinophilic CRSwNP standards, which are that CRSsNP and CRSwNP may be classified as eosinophilic when the percentage of eosinophils is 


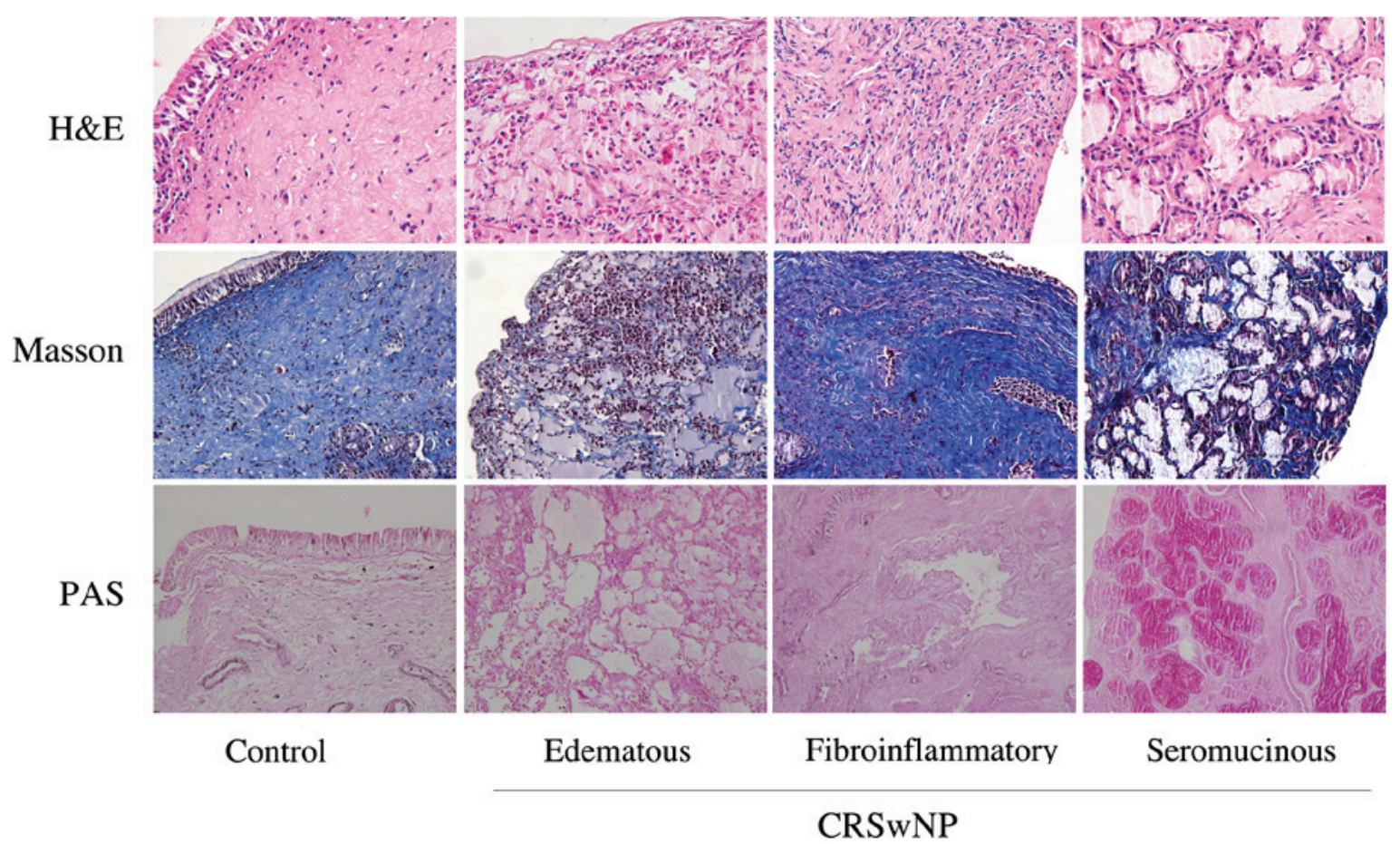

Figure 1. Morphological staining of the three type of tissues from patients with CRSwNP. H\&E stains the cytoplasm of eosinophilic cells red; the Masson trichrome stain colors collagen fibers blue; PAS stains the cytoplasm of mucous cells pink. The three types of stain enable CRSwNP to be divided into three types, namely the edematous $(n=40)$, fibroinflammatory $(n=15)$ and seromucinous $(n=16)$ types. Images from the control patients $(n=20)$ are also shown. Original magnification, 200x. H\&E, hematoxylin and eosin; CRSwNP, chronic rhinositus with nasal polyps; PAS, periodic acid Schiff.

A
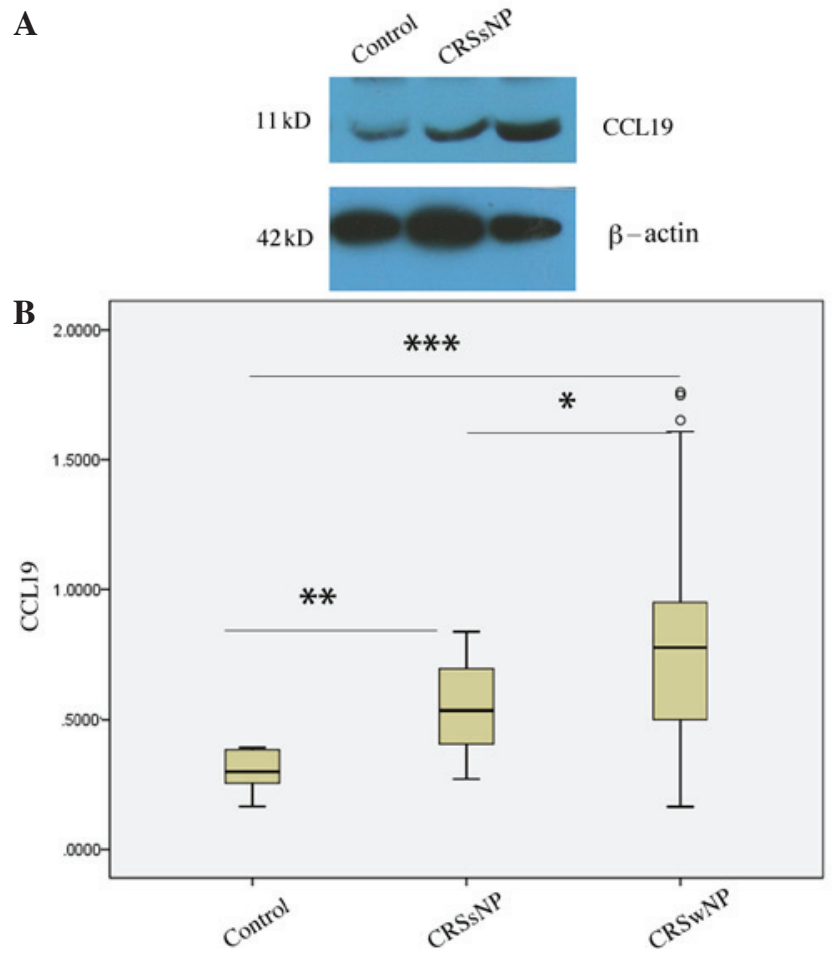

Figure 2. Expression levels of CCL19 protein in the ucinate process mucosa of patients with CRSsNP and in the polyps of patients with CRSwNP. (A) The expression levels of CCL19 protein were detected by western blotting and (B) semi-quantitative analysis showed that they were significantly increased in the patients with CRSsNP and CRSwNP compared with the controls. Results are expressed as median values. The non-parametric Kruskal-Wallis test was used; ${ }^{*} \mathrm{P}<0.05,{ }^{* *} \mathrm{P}<0.01,{ }^{* * *} \mathrm{P}<0.001$. Control $(\mathrm{n}=20), \mathrm{CRSsNP}(\mathrm{n}=21)$, CRSwNP ( $\mathrm{n}=71)$. CCL19, CC chemokine ligand 19; CRSsNP, chronic rhinosinusitis without nasal polyps; CRSwNP, chronic rhinosinusitis with nasal polyps.
$>10 \%$ of the mean of controls (2), the CRSwNP cases were further divided into 31 cases of eosinophilic type, and 40 cases of non-eosinophilic type. With a combination of Masson and PAS staining, the CRSwNP cases were divided into three types in accordance with their histopathological features: The edematous type, in which there are many eosinophilic granulocytes; the fibroinflammatory type, in which collagen fibers show significant proliferation with varying degrees of inflammatory cell infiltration, and the seromucinous type, in which mucous glands have clear evidence of hypertrophy. In this study, there were 40 cases of the edematous type, 15 cases of the fibroinflammatory type, and 16 cases of the seromucinous type. Representative images of the three different types are shown in Fig. 1.

Differential expression of CCL19 protein in CRSSNP and $C R S w N P$. According to the presence or absence of nasal polys, the patients with CRS were divided into CRSsNP and CRSwNP groups. The CCL19 protein levels in the CRSsNP $(\mathrm{P}=0.004)$ and $\mathrm{CRSwNP}(\mathrm{P}<0.001)$ groups were increased compared with those in the normal controls, and the CCL19 protein levels in the CRSwNP group were significantly higher than those observed in the CRSsNP group ( $\mathrm{P}=0.037$; Fig. 2).

Differential expression of CCL19 protein in eosinophilic and non-eosinophilic CRSwNP. Since eosinophilic and non-eosinophilic CRSwNP have different immunologic characteristics, CRSwNP was divided into eosinophilic and non-eosinophilic types. It was found that the CCL19 protein levels in the eosinophilic CRSwNP group were higher than those in the normal controls $(\mathrm{P}<0.001)$, the CRSsNP group 
$\mathbf{A}$

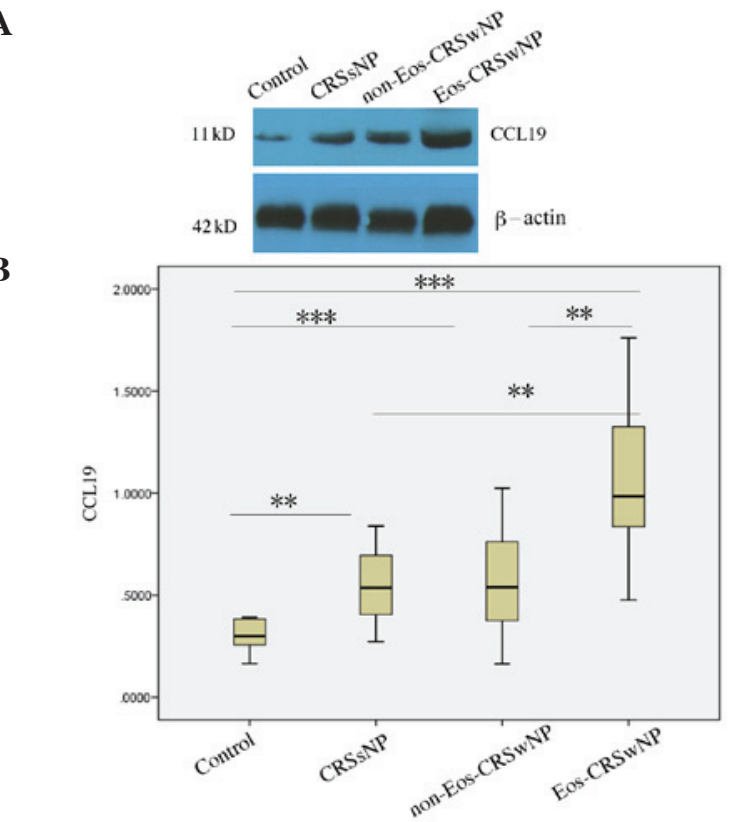

Figure 3. Expression levels of CCL19 protein in Eos- and non-Eos-CRSwNP. (A) Expression levels were detected by western blotting and (B) semi-quantitative analysis showed that they were increased significantly in Eos-CRSwNP compared with the controls. Results are expressed as median values. The non-parametric Kruskal-Wallis test was used; ${ }^{* *} \mathrm{P}<0.01,{ }^{* * * *} \mathrm{P}<0.001$. Control $(n=20)$, CRSsNP $(n=21)$, non-Eos-CRSwNP $(n=31)$, Eos-CRSwNP $(n=41)$. CCL19, CC chemokine ligand 19; Eos, eosinophilic; CRSsNP, chronic rhinosinusitis without nasal polyps; CRSwNP, chronic rhinosinusitis with nasal polyps.

A

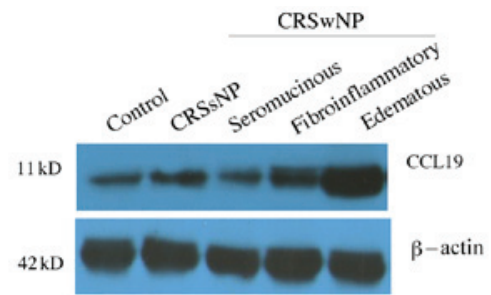

B

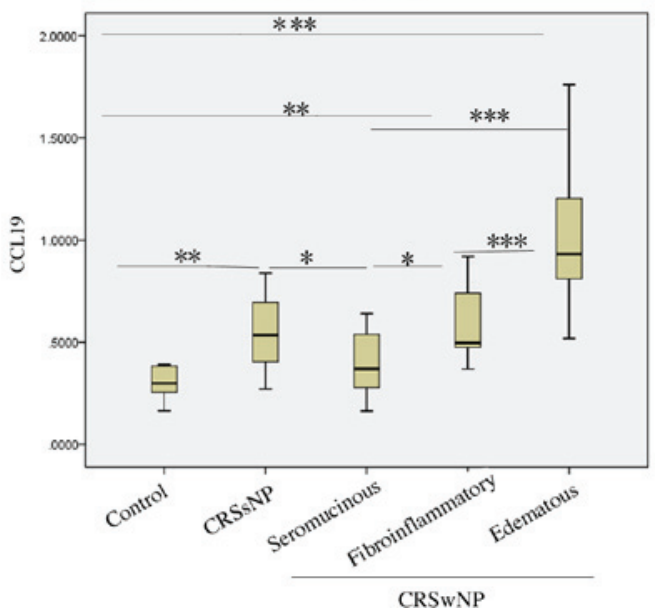

Figure 4. Expression levels of CCL19 protein in different histological types of CRSwNP. (A) Expression levels were detected by western blotting and (B) semi-quantitative analysis showed that they were increased significantly in the edematous and fibroinflammatory types of CRSwNP compared with the controls. Results are expressed as median values. The non-parametric Kruskal-Wallis test was used; ${ }^{*} \mathrm{P}<0.05,{ }^{* *} \mathrm{P}<0.01,{ }^{* * *} \mathrm{P}<0.001$. Control $(n=20)$, CRSsNP $(n=21)$, seromucinous CRSwNP $(n=16)$, fibroinflammatory CRSwNP ( $\mathrm{n}=15)$, and edematous CRSwNP $(\mathrm{n}=40)$. CCL19, CC chemokine ligand 19; CRSsNP, chronic rhinosinusitis without nasal polyps; CRSwNP, chronic rhinosinusitis with nasal polyps.
A

B

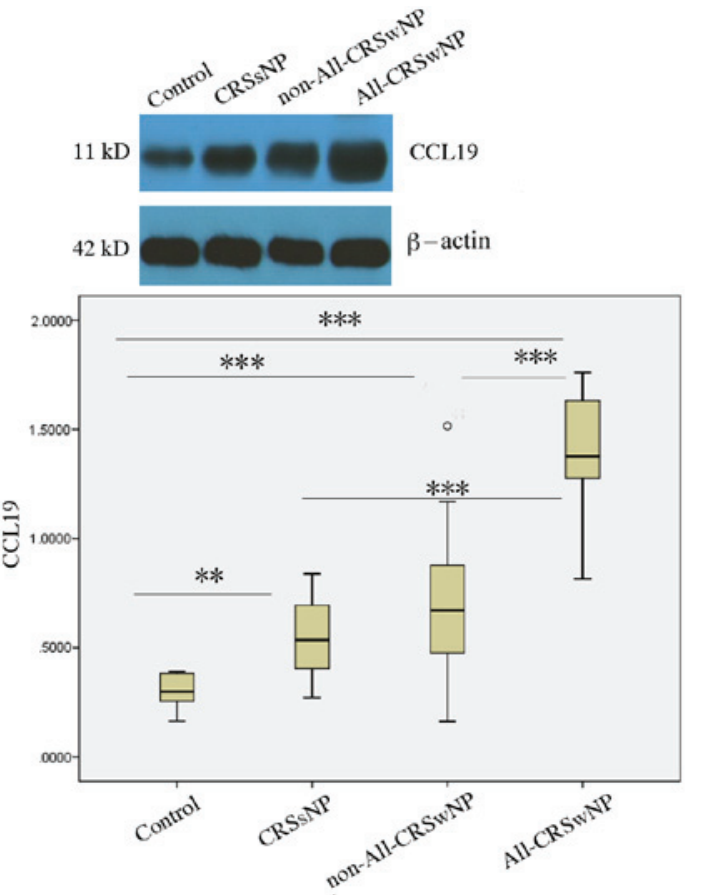

C

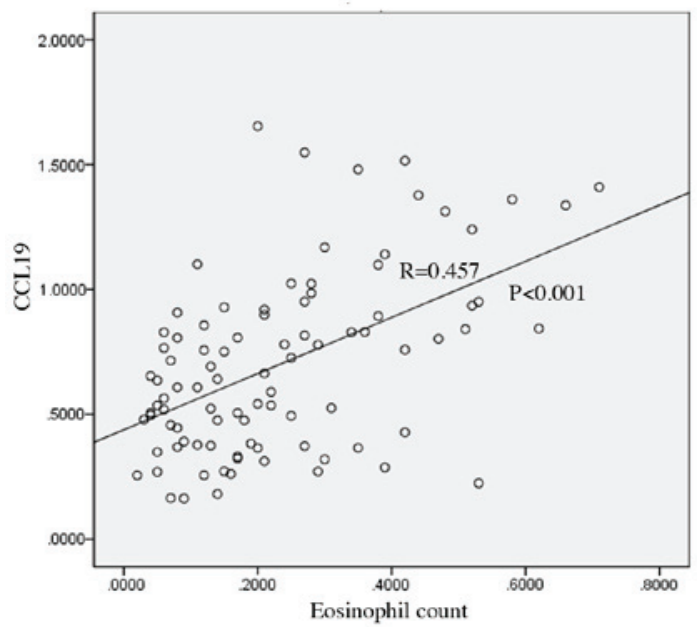

Figure 5. Correlation between CCL19 and eosinophils in blood and allergy. (A) Expression levels of CCL19 protein were detected by western blotting and (B) semi-quantitative analysis was conducted. Results are expressed as median values. (C) CCL19 levels were positively correlated with the blood eosinophil count (Spearman correlation coefficient $\mathrm{R}=0.457$ ), and (B) were significantly upregulated in CRSwNP patients with allergic rhinitis or asthma compared with those in the other three groups. The non-parametric Kruskal-Wallis test was used; ${ }^{* *} \mathrm{P}<0.01,{ }^{* * *} \mathrm{P}<0.001$. Control $(\mathrm{n}=20)$, CRSsNP $(\mathrm{n}=21), \mathrm{CRSwNP}(\mathrm{n}=71)$. CCL19, CC chemokine ligand 19; CRSsNP, chronic rhinosinusitis without nasal polyps; CRSwNP, chronic rhinosinusitis with nasal polyps; All, allergic rhinitis or asthma.

$(\mathrm{P}<0.01)$ and the non-eosinophilic $\mathrm{CRSwNP}$ group $(\mathrm{P}<0.01)$. In addition, the CCL19 protein levels in non-eosinophilic CRSwNP were higher than those observed in the normal controls $(\mathrm{P}<0.001)$, but were not significantly different from those in CRSsNP ( $\mathrm{P}=0.819$; Fig. 3).

Expression characteristics of CCL19 protein in different histological types of $C R S w N P$. According to its main tissue component and the nature of the infiltrative inflammatory cells, CRSwNP was divided into edematous, fibroinflammatory and seromucinous types. The CCL19 protein levels in the edematous type of CRSwNP were higher than those observed 


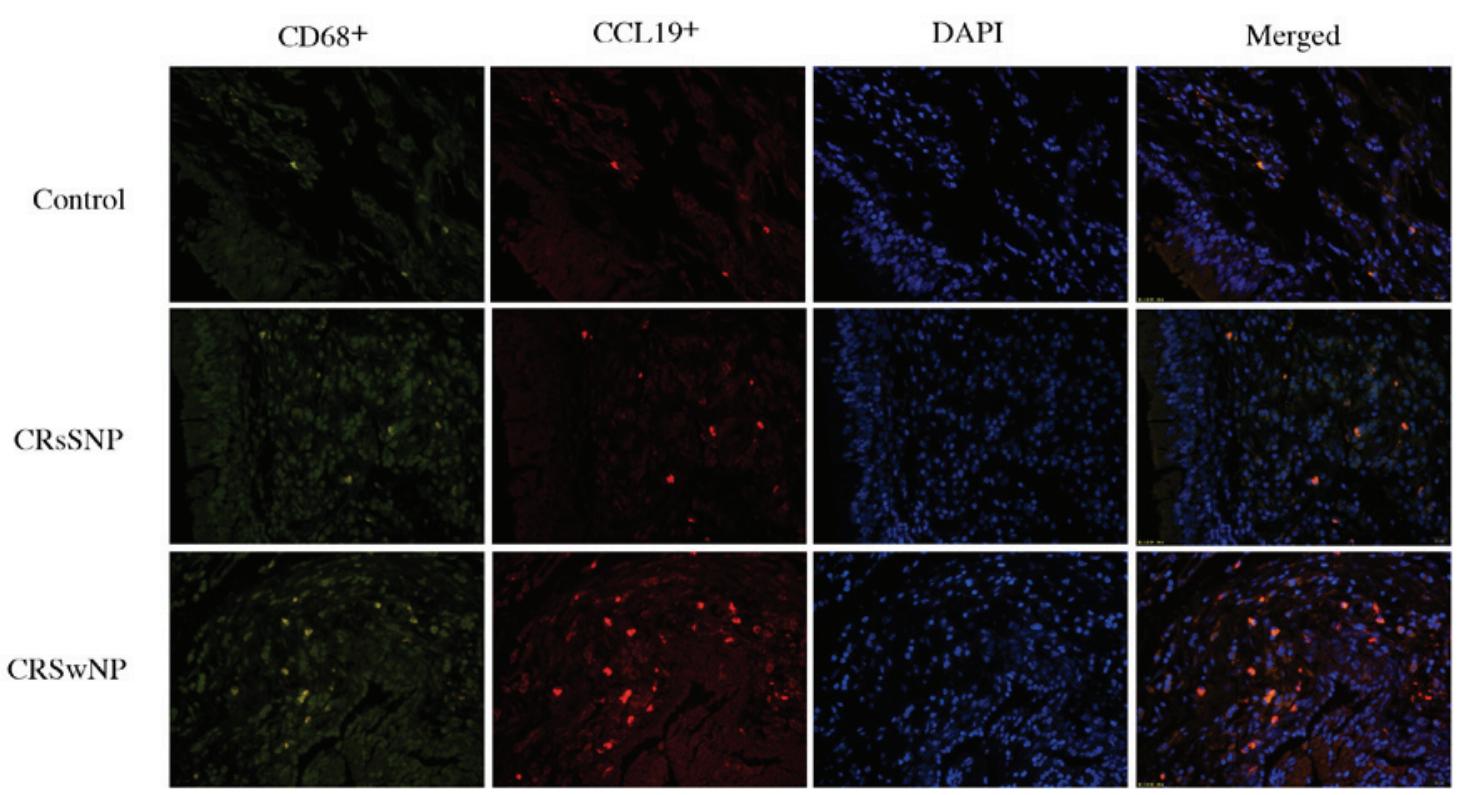

Figure 6. Cells expressing CCL19. Immunofluorescence was used to detect the expression of CCL19 in macrophages of normal controls and of patients with CRSsNP and CRSwNP. Anti-CCL19 (red), anti-CD68 monoclonal antibody (green) and nuclear DAPI (blue) counterstaining are shown. The results are from five independent patients. Control ( $\mathrm{n}=20)$, CRSsNP ( $\mathrm{n}=21)$, CRSwNP ( $\mathrm{n}=71)$. CCL19, CC chemokine ligand 19; CD68, cluster of differentiation 68; CRSsNP, chronic rhinosinusitis without nasal polyps; CRSwNP, chronic rhinosinusitis with nasal polyps; DAPI, 4,6-diamidino-2-phenyl indole.

in the normal controls, CRSsNP, and the fibroinflammatory and seromucinous types of CRSwNP (all, P<0.001). The CCL19 protein levels in the fibroinflammatory type of CRSwNP were higher than those in normal controls $(\mathrm{P}=0.004)$ and the seromucinous type $(\mathrm{P}=0.016)$, but were not significantly different from those in CRSsNP ( $\mathrm{P}=0.775)$. The CCL19 protein levels in the seromucinous type were lower than those of CRSsNP tissues $(\mathrm{P}=0.048)$, but not significantly different from those in normal controls ( $\mathrm{P}=0.140$; Fig. 4).

CCL19 protein levels correlate with blood eosinophilia and allergies. Since the CCL19 protein levels were significantly elevated in the edematous and eosinophilic types of CRSwNP, the possibility that CCL19 protein levels might correlate with peripheral blood eosinophilia and a history of allergy was investigated. Spearman correlation analysis showed that CCL19 protein levels were positively correlated with the number of eosinophils in the blood $(\mathrm{R}=0.457, \mathrm{P}<0.001)$, and the CCL19 protein levels in CRSwNP patients with allergic rhinitis or asthma were also significantly higher than in the patients with CRSsNP $(\mathrm{P}<0.001)$ and CRSwNP without allergy $(\mathrm{P}<0.001$; Fig. 5).

Macrophages in chronic rhinosinusitis highly express CCL19. Although the CCL19 protein levels in eosinophilic CRSwNP were high and correlated with the degree of blood eosinophilia, to the best of our knowledge, there are no reports concerning the expression of CCL19 by eosinophils in the literature. Eosinophils, macrophages and other cells are increasingly implicated in the pathophysiology of CRS. In addition, mature macrophages, dendritic cells and T cells can also express CCL19 (27). Using double-labeling immunofluorescence, it was found that CCL19+CD68 ${ }^{+}$ cells accounted for $72 \%$ of all CCL19+ cells. Therefore, the principal cells expressing CCL19 in CRS were CD68 ${ }^{+}$ macrophages (Fig. 6).

\section{Discussion}

CCL19 has a dual role, promoting the immune response or having anti-inflammatory and immunosuppressive effects. It has been reported that CCL19-knockout mice have more severe allergic features and an enhanced Th2 response compared with wild-type mice, and their allergic reactions were significantly inhibited when a plasmid encoding CCL19 DNA was used as gene therapy, with possible mechanisms including the promotion of IL-10 production, restriction of the function of dendritic cells, or the induction of apoptosis of mature dendritic cells $(17,18)$. CRS is a chronic inflammatory disease of the mucosa of the nasal cavity and paranasal sinuses. CRSsNP is based on a Th1 response characterized by elevated levels of granulocytes and interferon (IFN)- $\gamma$; by contrast, CRSwNP is dominated by Th2, mastocytes and eosinophilic infiltration $(2,28)$. The present study found that the CCL19 protein levels in CRSsNP and CRSwNP were significantly upregulated, particularly in eosinophilic and edematous CRSwNP. Since CCL19 has anti-inflammatory and immunosuppressive effects, its moderate increase in expression in inflammation may be associated with the restriction of eosinophil infiltration and tissue edema in CRSwNP $(22,23)$.

The present study found that CCL19 was expressed at the highest levels in the edematous and eosinophilic types of CRSwNP, and that its expression was higher in CRSwNP with a history of allergic rhinitis and asthma. Also, the expression of CCL19 was positively associated with the number of peripheral blood eosinophils, despite the fact that there are no reports concerning the expression of CCL19 by eosinophils in the literature. In addition to the Th2 response and eosinophilia, the 
role of macrophages in CRSwNP is coming under increasing scrutiny. Macrophages in different microenvironments can differentiate into different types. Under the influence of stimulation by IFN- $\gamma$ and lipopolysaccharide, they can differentiate into classical M1 macrophages to resist microbial infection, mainly secreting IFN- $\gamma$. By contrast, in the context of Th2 cytokines such as IL-4 and IL-13, they selectively differentiate into M2 macrophages, mainly secreting Th2 cytokines, and promoting allergic inflammation (13). Our previous study found that total counts of $\mathrm{CD}^{+} 8^{+}$macrophages in CRSsNP and CRSwNP were significantly upregulated compared with their levels in normal controls (2). The present study found using $\mathrm{CD} 8^{+}$and $\mathrm{CCL}_{19}{ }^{+}$double immunofluorescence that $72 \%$ of CCL19 was expressed by CD68 ${ }^{+}$cells in the submucosa. The expression of CCL19 in eosinophilic and edematous CRSwNP was significantly upregulated compared with that in non-eosinophilic CRSwNP. Thus, the upregulation of CCL19 in CRSwNP may be related to the increase in $\mathrm{CD}^{+} 8^{+}$macrophages, even if the kind of macrophage is not distinguished.

The main symptoms of patients with CRSwNP differ, but typically include nasal obstruction, olfactory dysfunction and/or rhinorrhea. These differences may be associated not only with the site and stage of CRSwNP, but also with its tissue types $(7,8)$. Hellquist (7) and Couto et al (8) have undertaken detailed research into the tissue types of CRSwNP and their classification, and divided CRSwNP into four types, namely edematous, seromucinous and fibroinflammatory types, and atypical hyperplasia. The edematous type is the most common type with higher levels of eosinophils in the nasal polyp, and a high relapse rate. The atypical hyperplasia type belongs to the category of benign hyperplasia, and is relatively rare $(7,8,27)$. In the present study, the CRSwNP cases included only edematous, seromucinous and fibroinflammatory types, with no typical hyperplasia samples. These findings were further confirmed by the observation of three different types of histopathological staining. The present study showed that the CCL19 protein levels in the edematous and fibroinflammatory CRSwNP were significantly upregulated compared with the controls. This suggests that CRSwNP with the upregulation of CCL19 has the main characteristics of inflammatory cell infiltration, tissue edema or fibrosis, which may correlate with a history of allergies. These factors may be considered to indicate that the use of glucocorticoid therapy postoperatively should be intensified.

In addition to macrophages, dendritic cells and other cells can also express CCL19 (24). Our previous study reported that dendritic cells were increased in the samples from patients with CRSsNP and CRSwNP compared with the controls, but the number of dendritic cells in CRSwNP was much less than that of macrophages (2). Double-labeling immunofluorescence demonstrated that CCL19 was mainly expressed by macrophages in CRSwNP. The previous study also found that the expression levels of IL-10 in CRSsNP and CRSwNP were significantly higher than those in the controls, with the highest levels in eosinophilic CRSwNP (2). In the present study, we found that the CCL19 protein levels were the highest in eosinophilic CRSwNP, allowing us to speculate that the upregulated CCL19 in CRSwNP may promote the expression of immune-suppressive factor IL-10, thus limiting the inflammatory cascade, which is consistent with a previous study (22).
Ocampo et al (29) demonstrated that CCL19 mRNA expression was elevated in CRSwNP. Consistent with their study, the present study confirmed that CCL19 protein expression was also upregulated in CRSwNP and CRSsNP, and correlated with different histologic features of CRSwNP.

Determining the exact mechanism, however, will require a high fidelity CRSwNP animal model with CCL19 gene knockout, plus assessment of the therapeutic effect of recombinant CCL19 in such a model. The present study is also limited by the lack of analysis of expression of the CCL19 receptor CCR7 in CRSwNP $(22,23)$, and the role of specific receptors and their ligands in the pathogenesis of CRSwNP remains unknown. Blood eosinophil counts are simple and affordable to obtain, and it has been reported that they have diagnostic significance for eosinophilic CRSwNP (30). Therefore, in the present study, the correlation between CCL19 and eosinophils was analyzed, but the correlation with CD68 was not.

In conclusion, this study shows that CCL19 is mainly expressed by an expanded population of $\mathrm{CD} 68^{+}$macrophages in CRSwNP, and positively correlates with eosinophil counts in the blood and with a history of allergy. The upregulation of CCL19 may play a protective role in limiting eosinophil infiltration and the extent of edema to provide anti-inflammatory and immunomodulatory effects.

\section{Acknowledgements}

This study was supported by the Joint Fund of 2012 from the Health Nonprofit Industry Research Project of National Ministry of Health, China (grant no. 201202005), the National Natural Science Foundation of China (grant no. 81070766) and the Natural Science Foundation of Hubei Province, China (grant no. 2012FFB04312).

\section{References}

1. Shi JB, Fu QL, Zhang H, Cheng L, Wang YJ, Zhu DD, Lv W, Liu SX, Li PZ, Ou CQ and Xu G: Epidemiology of chronic rhinosinusitis: Results from a cross-sectional survey in seven Chinese cities. Allergy 70: 533-539, 2015.

2. Cao PP, Li HB, Wang BF, Wang SB, You XJ, Cui YH, Wang DY, Desrosiers $\mathrm{M}$ and Liu Z: Distinct immunopathologic characteristics of various types of chronic rhinosinusitis in adult Chinese. J Allergy Clin Immunol 124: 478-484, 2009.

3. Akdis CA, Bachert C, Cingi C, Dykewicz MS, Hellings PW, Naclerio RM, Schleimer RP and Ledford D: Endotypes and phenotypes of chronic rhinosinusitis: A PRACTALL document of the European Academy of Allergy and Clinical Immunology and the American Academy of Allergy, Asthma \& Immunology. J Allergy Clin Immunol 131: 1479-1490, 2013.

4. Feazel LM, Robertson CE, Ramakrishnan VR and Frank DN: Microbiome complexity and Staphylococcus aureus in chronic rhinosinusitis. Laryngoscope 122: 467-472, 2012.

5. Polzehl D, Moeller P, Riechelmann H and Perner S: Distinct features of chronic rhinosinusitis with and without nasal polyps. Allergy 61: 1275-1279, 2006.

6. Kanda A, Fleury S, Kobayashi Y, Tomoda K, Julia V, Dombrowicz D: Th2-activated eosinophils release Th1 cy tokines that modulate allergic inflammation. Allergology Int 64 (Suppl): S71-S73, 2015.

7. Hellquist HB: Nasal polyps update. Histopathology. Allergy Asthma Proc 17: 237-242, 1996.

8. Couto LG, Fernades AM, Brandão DF, Santi Neto D, Valera FC and Anselmo-Lima WT: Histological aspects of rhinosinusal polyps. Braz J Otorhinolaryngol 74: 207-212, 2008.

9. Shi LL, Xiong P, Zhang L, Cao PP, Liao B, Lu X, Cui YH and Liu Z: Features of airway remodeling in different types of Chinese chronic rhinosinusitis are associated with inflammation patterns. Allergy 68: 101-109, 2013. 
10. Yoshikawa M, Wada K, Yoshimura T, Asaka D, Okada N, Matsumoto K and Moriyama H: Increased CXCL10 expression in nasal fibroblasts from patients with refractory chronic rhinosinusitis and asthma. Allergol Int 62: 495-502, 2013.

11. El-Shazly AE, Doloriert HC, Bisig B, Lefebvre PP, Delvenne P and Jacobs N: Novel cooperation between CX3CL1 and CCL26 inducing NK cell chemotaxis via CX3CR1: A possible mechanism for NK cell infiltration of the allergic nasal tissue. Clin Exp Allergy 43: 322-331, 2013.

12. Wu X, Mimms R, Lima R, Peters-Hall J, Rose MC and Peña MT: Localization of inflammatory mediators in pediatric sinus mucosa. Arch Otolaryngol Head Neck Surg 138: 389-397, 2012.

13. Peterson S, Poposki JA, Nagarkar DR, Chustz RT, Peters AT, Suh LA, Carter R, Norton J, Harris KE, Grammer LC, et al: Increased expression of $\mathrm{CC}$ chemokine ligand 18 in patients with chronic rhinosinusitis with nasal polyps. J Allergy Clin Immunol 129: 119-127. e1-e9, 2012.

14. Petrek M, Kolek V, Szotkowská J and du Bois RM: CC and $\mathrm{C}$ chemokine expression in pulmonary sarcoidosis. Eur Respir J 20: 1206-1212, 2002.

15. Kalwitz G, Andreas K, Endres M, Neumann K, Notter M, Ringe J, Sittinger $M$ and Kaps C: Chemokine profile of human serum from whole blood: Migratory effects of CXCL-10 and CXCL-11 on human mesenchymal stem cells. Connect Tissue Res 51: 113-122, 2010.

16. Ozdemir C, Akdis $M$ and Akdis CA: T-cell response to allergens. Chem Immunol Allergy 95: 22-44, 2010.

17. Barnes PJ: Pathophysiology of allergic inflammation. Immunol Rev 242: 31-50, 2011.

18. Kellermann SA, Hudak S, Oldham ER, Liu YJ and McEvoy LM The CC chemokine receptor-7 ligands 6Ckine and macrophage inflammatory protein-3 beta are potent chemoattractants for in vitro- and in vivo-derived dendritic cells. J Immunol 162: 3859-3864, 1999.

19. Kim CH, Pelus LM, White JR, Applebaum E, Johanson K and Broxmeyer HE: CK beta-11/macrophage inflammatory protein-3 beta/EBI1-ligand chemokine is an efficacious chemoattractant for T and B cells. J Immunol 160: 2418-2424, 1998.

20. Rangel-Moreno J, Moyron-Quiroz J, Kusser K, Hartson L, Nakano $\mathrm{H}$ and Randall TD: Role of CXC chemokine ligand 13, CC chemokine ligand (CCL) 19, and CCL21 in the organization and function of nasal-associated lymphoid tissue. $J$ Immunol 175: 4904-4913, 2005.
21. Ellingsen T, Hansen I, Thorsen J, Møller BK, Tarp U, Lottenburger T, Andersen LS, Skjødt H, Pedersen JK, Lauridsen UB, et al: Upregulated baseline plasma CCL19 and CCR7 cell-surface expression on monocytes in early rheumatoid arthritis normalized during treatment and CCL19 correlated with radiographic progression. Scandinavian J Rheumatol 43: 91-100, 2014

22. Yamashita N, Tashimo H, Matsuo $Y$, Ishida H, Yoshiura $K$, Sato K, Yamashita N, Kakiuchi T and Ohta K: Role of CCL21 and CCL19 in allergic inflammation in the ovalbumin-specific murine asthmatic model. J Allergy Clin Immunol 117: 1040-1046, 2006.

23. Bosè F, Petti L, Diani M, Moscheni C, Molteni S, Altomare A, Rossi RL, Talarico D, Fontana R, Russo V, et al: Inhibition of CCR7/CCL19 axis in lesional skin is a critical event for clinical remission induced by TNF blockade in patients with psoriasis. Am J Pathol 183: 413-421, 2013.

24. Middel P, Raddatz D, Gunawan B, Haller F and Radzun HJ: Increased number of mature dendritic cells in Crohn's disease: Evidence for a chemokine mediated retention mechanism. Gut 55: 220-227, 2006

25. Takamura K, Fukuyama S, Nagatake T, Kim DY, Kawamura A, Kawauchi $\mathrm{H}$ and Kiyono $\mathrm{H}$ : Regulatory role of lymphoid chemokine CCL19 and CCL21 in the control of allergic rhinitis. J Immunol 179: 5897-5906, 2007.

26. Fokkens WJ, Lund VJ, Mullol J, Bachert C, Alobid I, Baroody F, Cohen N, Cervin A, Douglas R, Gevaert P, et al: European position paper on rhinosinusitis and nasal polyps 2012. Rhinol 50 (Suppl 23): 1-298, 2012.

27. Robbiani DF, Finch RA, Jäger D, Muller WA, Sartorelli AC, Randolph GJ: The leukotriene C(4) transporter MRP1 regulates CCL19 (MIP-3 $\beta$, ELC)-dependent mobilization of dendritic cells to lymph nodes. Cell 103: 757-768, 2000.

28. Van Zele T, Holtappels G, Gevaert P and Bachert C: Differences in initial immunoprofiles between recurrent and nonrecurrent chronic rhinosinusitis with nasal polyps. Am J Rhinol Allergy 28: 192-198, 2014.

29. Ocampo CJ,. Kato A, Norton J, Kern RC, Conley DB, Chandra R, Tan B, Peters AT. Grammer LC and Schleimer RP. Elevated expression of mRNA for CCL2, CCL19, CCR7 and CXCR3 in chronic rhinosinusitis with nasal polyposis. J Allergy Clin Immunol 129 (Suppl): AB43, 2012.

30. Hu Y, Cao PP, Liang GT, Cui YH and Liu Z: Diagnostic significance of blood eosinophil count in eosinophilic chronic rhinosinusitis with nasal polyps in Chinese adults. Laryngoscope 122: 498-503, 2012. 